|| ISSN(online): 2589-8698 || ISSN(print): 2589-868X ||

International Journal of Medical and Biomedical Studies Available Online at www.ijmbs.info

NLM (National Library of Medicine ID: 101738825)

Index Copernicus Value 2019: 79.34

Original Research Article

Volume 5, Issue 9; September: 2021; Page No. 13-14

\title{
TO STUDY THE RISK FACTORS ETIOLOGY OF ACUTE PANCREATITIS
}

\author{
${ }^{1}$ Dr. Devendra Singh, ${ }^{2} \mathrm{Dr}$. Ravindra Singh \\ ${ }^{1,2}$ M S General Surgery \\ ${ }^{1}$ Department of Surgery, RUHS Medical College and Hospital, Jaipur \\ ${ }^{2}$ Department of Surgery, RNT Medical College and Maharana Bhupal Govt. Hospital, Udaipur
}

Article Info: Received 08 July 2021; Accepted 28 August 2021

DOI: https://doi.org/10.32553/ijmbs.v5i9.2173

Corresponding author: Dr. Ravindra Singh

Conflict of interest: No conflict of interest.

\begin{abstract} which account for approximately $75-80 \%$ of all cases of acute pancreatitis Udaipur. A total of 35 cases of acute pancreatitis were studied gall stone pancreatitis. In $8(22.8 \%)$ patient cause was undetected.

Keywords: Risk factor, Pancreatitis, Gall sone

\section{Introduction}

The most important aetiological factors for acute pancreatitis are either biliary tract stone disease or alcohol, which account for approximately $75-80 \%$ of all cases of acute pancreatitis. $^{1}$

Other causes are infrequent and include a variety of infections, hyper triglyceridaemia, hypercalcaemia, hypothermia, pancreatic and ampullary tumours, exposure to a variety of pancreatotoxic drugs and hereditary pancreatitis. $^{2}$
\end{abstract}

Background: The most important aetiological factors for acute pancreatitis are either biliary tract stone disease or alcohol,

Methods: This study was conducted in the department of surgery, RNT Medical College and Maharana Bhupal Govt. Hospital,

Results: In our study of 35 cases of acute pancreatitis, 14(40\%) patient had alcoholic pancreatitis, while 13(37.2\%) patient had

Conclusion: Alcohol abuse and gall stones were main etiological factors with almost equal frequency.

Acute pancreatitis can also be a consequence of trauma (including iatrogenic damage such as abdominal surgery and ERCP). ${ }^{3}$

Cases without an obvious cause are referred to as idiopathic and should account for less than $20 \%$ of all cases, according to guidelines (UK Guidelines, 2005.)

\section{Materials and Methods}

This study was conducted in the department of surgery, RNT Medical College and Maharana Bhupal Govt. Hospital, Udaipur. A total of 35 cases of acute pancreatitis were studied.

\section{Inclusion Criteria:}

The diagnostic criteria for acute pancreatitis were those defined by the 2006 AP Guidelines, as the presence of at least two of the following features(Banks PA, 2006).

1) Characteristic abdominal pain;
2) Elevation over 3 times the upper normal limit of serum amylase/ lipase;

3) Characteristic features on computer tomography (CT) scan.

\section{Exclusion Criteria:}

Patients of chronic pancreatitis were excluded from this study.

Detailed clinical evaluation of all these patients was done and following data were recorded:

- Detailed history of the patient, with special emphasis on symptoms of acute pain abdomen, nausea vomiting.

- History of co morbid conditions, including gall stone, trauma,

- History of personal habits, including dietary history, history of alcohol intake.

- General Physical examination, with special emphasis on presence of fever, hypovolemia and shock.

- Abdominal examination, including presence of tenderness and/or lump in epigestrium.

- Grey turner's sign (bruising of the flanks).

- Cullen's sign and (superficial edema and bruising in the subcutaneous fatty tissue around the umbilicus).

- Mayo-Robson's sign (pain while pressing at the top of the angle lateral to the Erector spinae muscles and below the left $12^{\text {th }}$ rib (left cost vertebral angle). 
$>$ All the patients were investigated for basic investigations like:

Complete Blood Count, Blood Sugar, Blood Urea, Serum Creatinine, Urine Routine and Microscopy

$>$ Radiology: X-ray chest and flat plate abdomen, ultraSonography abdomen and pelvis. CT scan of abdomen and pelvis, MRI of abdomen and pelvis.

$>$ Specific Investigations-

- Serum amylase

- Serum lipase
- Serum LDH

- Serum calcium

These patients were evaluated on Ranson criteria

\section{Results}

The incidence of acute pancreatitis was highest in the $4^{\text {th }}$ decade $(25.70 \%)$ followed by $5^{\text {th }}$ decade $(20 \%)$ and then the $6^{\text {th }}$ decade $(17.14 \%)$. Incidence was less in both the extremes of ages. The youngest patient in the study was 17 years and the eldest was 72 years. $71 \%$ of the cases were male and 28 $\%$ were female. So male to female ratio in our study was about 5:2

Table 1: Distribution of patients based on causative factor

\begin{tabular}{|l|c|c|}
\hline Cause & No. of patients & Percentage \\
\hline Alcohol & 14 & $40 \%$ \\
\hline Cholelithiasis & 13 & $37.1 \%$ \\
\hline Other & 8 & $22.9 \%$ \\
\hline Total & 35 & $100 \%$ \\
\hline
\end{tabular}

This table shows that out of 35 cases of acute pancreatitis, $14(40 \%)$ patient had alcoholic pancreatitis, while $13(37.1 \%)$ patient had gall stone pancreatitis. In $8(22.8 \%)$ patient cause was undetected.

\section{Discussion}

In our study of 35 cases of acute pancreatitis, 14(40\%) patient had alcoholic pancreatitis, while 13(37.2\%) patient had gall stone pancreatitis. In $8(22.8 \%)$ patient cause was undetected.

According to J H Ranson (1985) 3 the etiology of pancreatitis was prolonged alcohol abuse in 50(60\%) patients, gallstones in 12(14\%), alcohol and gallstones both in 5(6\%), miscellaneous or unknown in $16(19 \%)$ patients.

Bohidaret al. $(2003)^{4}$ found the causes of pancreatitis were gallstones in $48 \%$, alcohol in $28 \%$, and others in $24 \%$ of the patients.

In study by Marco et al. (2011) ${ }^{5}$ most common etiology was alcohol consumption (39.3\%), followed by gallstones (24.1\%). In 31.9\% no identifiable cause was found.

In study of Paul et al. (1999) ${ }^{6}$ the main Etiology was biliary in $39 \%$ patients and alcohol abuse in $33 \%$; other aetiologies were present in $8 \%$, and etiology remained unknown in $20 \%$.

\section{Conclusion}

Alcohol abuse and gall stones were main etiological factors with almost equal frequency.

\section{References}

1. McKay AJ, Imrie CW, O'Neill J, Duncan JG. Is an early ultrasound scan of value in acute pancreatitis? Br J Surg 1982; 69:369-372.

2. Uhl W, Buchler MW, Malfertheiner P, et al. A randomised, double-blind, multicentre trial of Octreotide in moderate to severe acute pancreatitis. Gut 1999; 45:97-104

3. Ranson JH, Rifkind KM, Turner JW. Prognostic signs and nonoperative peritoneal lavage in acute pancreatitis. SurgGynecolObstet 1976 Aug; 143(2):209-19.

4. Birgisson $\mathrm{H}$, Moller PH, Birgisson S, Thoroddsen A, Asgeirsson KS, Sigurjonsson SV, Magnusson J. Acute pancreatitis: a prospective study of its incidence, aetiology, severity and mortality in Iceland. Eur J Surg 2002; 168:278-282.

5. Marco Simoesa, b, Patricia Alvesa, HelderEspertoa, Catarina Canhaa, Elisa Meiraa, Erica Ferreiraa,ManuelGomesa, Isabel Fonsecaa, BenildeBarbosaa, Jose Nascimento Costaa. Predicting Acute Pancreatitis Severity: Comparison of Prognostic Scores. Elmer Press 2011; 218-219.

6. Peter A, Banks, MACG, Martin L, Freeman FACG. Practice Guidelines in Acute Pancreatitis. Am J Gastroenterol 2006; 101:2379-2400. 